\title{
First Name
}

National Cancer Institute

\section{Source}

National Cancer Institute. First Name. NCI Thesaurus. Code C40974.

A word or group of words indicating a person's first (personal or given) name; the name that precedes the surname. 